\title{
ÉSTERES DE CLOROPROPANÓIS E DE GLICIDOL EM ALIMENTOS
}

\author{
Adriana Pavesi Arisseto*, Priscila Francisca Corrêa Marcolino e Eduardo Vicente \\ Centro de Ciência e Qualidade de Alimentos, Instituto de Tecnologia de Alimentos, Avenida Brasil 2880, 13070-178 Campinas \\ - SP, Brasil \\ Klicia Araújo Sampaio \\ Faculty of Bioscience Engineering, Ghent University, Coupure Links 653, B-9000, Ghent, Belgium
}

Recebido em 2/4/13; aceito em 11/7/13; publicado na web em 9/8/13

\begin{abstract}
CHLOROPROPANOLS AND GLYCIDYL ESTERS IN FOODS. Chloropropanols are a well-known group of food processing contaminants. They are formed through the reaction between lipids and chlorides when submitted to thermal treatment, and can be found in free and bound form. Although free chloropropanols were identified around 30 years ago, the occurrence of bound forms, especially 3-MCPD, and glycidyl fatty acid esters, has only recently been reported in several food products. Dietary exposure to these ester-bound compounds has been considered a priority food safety issue since free forms can be potentially released through the action of gut lipases, representing a major toxicological concern.
\end{abstract}

Keywords: 3-MCPD esters; glycidyl esters; oil refining.

\section{INTRODUÇÃO}

A formação de compostos tóxicos durante o processamento de alimentos tem sido considerada uma importante questão em relação à segurança alimentar. Estes compostos, que não são detectados na matéria-prima, podem ser formados por reações químicas entre substâncias naturalmente presentes e/ou adicionadas aos alimentos, durante processos envolvendo a utilização de altas temperaturas, fermentação, hidrólise e defumação, entre outros. A preocupação associada à ocorrência de tais contaminantes na dieta se justifica pelos riscos que eles podem representar à saúde do consumidor, uma vez que muitos deles são considerados possíveis ou prováveis agentes carcinógenos em seres humanos. ${ }^{1}$

Embora a exposição humana a estas substâncias esteja ocorrendo há algumas gerações, sua presença em alimentos começou a ser descoberta somente por volta de 1960. Alguns exemplos incluem a identificação de N-nitrosaminas em peixes e carnes curadas, de aminas heterocíclicas em carnes e peixes grelhados e de cloropropanóis, entre eles o 3-monocloropropano-1,2-diol (3-MCPD), em proteína vegetal hidrolisada..$^{2-4} \mathrm{Na}$ última década, esta classe de contaminantes recebeu uma atenção ainda maior, devido à descoberta da formação de acrilamida e furano durante o tratamento térmico de uma grande variedade de alimentos que são regularmente consumidos pela população. ${ }^{5,6}$ Adicional interesse por estes compostos foi despertado após a detecção de altos níveis de 3-MCPD ligado a ácidos graxos (ésteres de 3-MCPD) em diversos alimentos processados. ${ }^{7}$

A presença de ésteres de 3-MCPD em alimentos levantou uma preocupação imediata na comunidade científica mundial devido à possibilidade destes compostos representarem uma fonte adicional de exposição ao 3-MCPD, até então não conhecida, caso fossem hidrolisados pelas enzimas do sistema digestivo humano. ${ }^{8-11}$ Esta preocupação justifica-se pelo fato de que o 3-MCPD tem mostrado propriedades nefrotóxicas bem como capacidade de afetar a fertilidade e de induzir câncer em experimentos realizados com animais. ${ }^{12}$

Em um estudo preliminar realizado na Alemanha, considerando-se os níveis de ésteres de 3-MCPD encontrados em alimentos e assumindo que $100 \%$ destes ésteres são hidrolisados durante a digestão,

*e-mail: adriana.arisseto@gmail.com foi possível verificar que a exposição da população adulta ao 3-MCPD poderia ultrapassar em até cinco vezes o valor da ingestão diária máxima tolerável provisória (PMTDI) de $2 \mu \mathrm{g} / \mathrm{kg}$ de peso corpóreo (pc) estabelecida atualmente para este composto, sugerindo um risco potencial à saúde. Utilizando o mesmo princípio para a população infantil, os resultados obtidos foram ainda mais preocupantes, mostrando que a PMTDI poderia ser ultrapassada em até 20 vezes. ${ }^{8}$

As informações disponíveis sobre a ocorrência de ésteres de 3-MCPD e de outros cloropropanóis em alimentos ainda são limitadas, mas progressos significativos têm sido alcançados nos últimos anos em relação ao aperfeiçoamento de métodos analíticos, à elucidação dos principais mecanismos de formação, à identificação das principais fontes de exposição na dieta, ao desenvolvimento de estratégias que minimizem sua formação e à avaliação do seu potencial tóxico bem como dos riscos que podem representar à saúde humana. Esta revisão apresenta os aspectos relevantes de estudos que têm contribuído para os avanços do conhecimento relacionado à presença destes compostos em alimentos. Considerações sobre as recentes descobertas da formação de ésteres de glicidol também são apresentadas.

\section{CLOROPROPANÓIS E SEUS ÉSTERES}

O termo cloropropanóis é utilizado para definir um grupo de contaminantes químicos derivados do glicerol, caracterizados estruturalmente por álcoois e dióis de três carbonos ligados a um ou dois átomos de cloro. ${ }^{13}$ Diferentes compostos, entre eles monocloropropanodióis (MCPDs) e dicloropropanóis (DCPs), foram identificados como contaminantes de proteína vegetal hidrolisada por ácido clorídrico (PVH ácida) há aproximadamente 30 anos..$^{4,14,15}$ Nestes estudos, observou-se que o 3-MCPD era o cloropropanol encontrado em maior abundância, seguido pelo 2-monocloropropano-1,3-diol (2-MCPD), 2,3-dicloropropan-1-ol (2,3-DCP) e 1,3-dicloropropan-2-ol (1,3DCP), em concentrações relativas de 10, 1 e 0,1\%, respectivamente. Posteriormente, foi observado que o 2,3-DCP e o 3-MCPD são encontrados como misturas racêmicas de seus $(R)$ - e $(S)$-enantiômeros. ${ }^{16}$

Os ésteres de cloropropanóis correspondem a estruturas de cloropropanóis nas quais grupos hidroxilas estão esterificados com ácidos graxos. Similarmente aos cloropropanóis, seus ésteres podem 
ser classificados em ésteres de MCPD e ésteres de DCP, dependendo do número de átomos de cloro da molécula. Ésteres de MCPD podem ser divididos em ésteres de 3-MCPD e ésteres de 2-MCPD, enquanto que ésteres de DCP podem ser divididos em ésteres de 2,3-DCP e ésteres de 1,3-DCP, de acordo com a posição do cloro na molécula. Ésteres de 3-MCPD e de 2-MCPD podem ainda ser subdivididos em monoésteres e diésteres, dependendo do grau de esterificação dos grupos hidroxilas da molécula (parcial ou total). No caso dos monoésteres de 3-MCPD, estes ainda podem ser separados em 1- e 2-monoésteres de 3-MCPD, conforme a posição da cadeia de ácido graxo. ${ }^{17}$ A Tabela 1 mostra as estruturas químicas de cloropropanóis e de seus ésteres.

Tabela 1. Estruturas químicas dos cloropropanóis e seus ésteres

\begin{tabular}{|c|c|c|c|}
\hline Cloropropanóis & Ésteres de clor & propanóis & \\
\hline $\begin{array}{l}\mathrm{CH}_{2}-\mathrm{OH} \\
{ }_{\mathrm{CH}}-\mathrm{OH} \\
{ }_{\mathrm{CH}}-\mathrm{Cl}\end{array}$ & $\begin{array}{l}\mathrm{O} \\
\left.\right|_{\mathrm{CH}_{2}-\mathrm{Cl}} ^{\mathrm{CH}_{2}-\mathrm{O}-\mathrm{O}-\mathrm{C}^{\prime \prime}}-\mathrm{O} \\
\mathrm{O}\end{array}$ & $\left.\right|_{\mathrm{CH}_{2}-\mathrm{Cl}} ^{\mathrm{CH}_{2}-\mathrm{O}-\mathrm{C}^{\prime \prime}-\mathrm{R}}$ & $\left.\right|_{\mathrm{CH}_{2}-\mathrm{Cl}} ^{\mathrm{CH}_{2}-\mathrm{OH}} \mathrm{O}-\mathrm{O}-\mathrm{C}-\mathrm{R}$ \\
\hline $\begin{array}{l}\text { 3-monocloropropano-1,2-diol } \\
\text { (3-MCPD) }\end{array}$ & Diéster de 3-MCPD & 1-monoéster de 3-MCPD & 2-monoéster de 3-MCPD \\
\hline $\begin{array}{l}\mathrm{CH}_{2}-\mathrm{OH} \\
\stackrel{\mathrm{CH}}{\mathrm{C}}-\mathrm{Cl} \\
\mathrm{CH}_{2}-\mathrm{OH}\end{array}$ & $\begin{array}{l}\stackrel{\mathrm{O}}{\mathrm{CH}_{2}-\mathrm{O}-\mathrm{C}^{\prime \prime}-\mathrm{R}} \\
\mathrm{C}_{\mathrm{CH}}-\mathrm{Cl} \\
\mathrm{CH}_{2}-\mathrm{O}-\mathrm{C}^{\prime \prime}-\mathrm{R}\end{array}$ & $\begin{array}{l}\quad \mathrm{O} \\
\left.\right|_{\mathrm{CH}} \mathrm{CH}_{2}-\mathrm{O}-\mathrm{Cl}^{\prime \prime}-\mathrm{R} \\
\mathrm{CH}_{2}-\mathrm{OH}\end{array}$ & \\
\hline $\begin{array}{l}\text { 2-monocloropropano-1,3-diol } \\
\text { (2-MCPD) }\end{array}$ & Diéster de 2-MCPD & Monoéster de 2-MCPD & \\
\hline $\begin{array}{l}\mathrm{CH}_{2}-\mathrm{OH} \\
\mathrm{CH}_{-}-\mathrm{Cl} \\
\mathrm{CH}_{2}-\mathrm{Cl}\end{array}$ & $\begin{array}{l}\stackrel{\mathrm{O}}{\mathrm{CH}_{2}-\mathrm{O}-\mathrm{C}^{\prime \prime}-\mathrm{R}} \\
\mathrm{CH}_{\mathrm{CH}}-\mathrm{Cl} \\
{ }_{\mathrm{CH}}-\mathrm{Cl}\end{array}$ & & \\
\hline $\begin{array}{l}\text { 2,3-dicloropropan-1-ol } \\
\quad(2,3-D C P)\end{array}$ & Éster de 2,3-DCP & & \\
\hline $\begin{array}{l}\mathrm{CH}_{2}-\mathrm{Cl} \\
\stackrel{\mathrm{CH}}{-\mathrm{OH}} \\
\mathrm{CH}_{2}-\mathrm{Cl}\end{array}$ & $\begin{array}{l}\mathrm{CH}_{2}-\mathrm{Cl} \quad \mathrm{O} \\
\mathrm{CH}_{\mathrm{CH}}-\mathrm{O}-\mathrm{C}-\mathrm{R} \\
\mathrm{CH}_{2}-\mathrm{Cl}\end{array}$ & & \\
\hline $\begin{array}{l}\text { 1,3-dicloropropan-2-ol } \\
\text { (1,3-DCP) }\end{array}$ & Éster de 1,3-DCP & & \\
\hline
\end{tabular}

$\mathrm{R}$ = grupo alquila.

As pesquisas relacionadas aos ésteres de cloropropanóis em alimentos têm sido focadas na ocorrência de ésteres de 3-MCPD, devido a sua maior abundância. Dados preliminares disponíveis sobre ésteres de outros cloropropanóis indicam que ésteres de 2-MCPD podem estar presentes em quantidades inferiores às de ésteres de 3-MCPD, enquanto que ésteres de 1,3-DCP não têm sido detectados. ${ }^{18-20}$

\section{ASPECTOS TOXICOLÓGICOS}

\section{Hidrólise, absorção e metabolismo}

Até o presente, a preocupação primária em relação à presença de ésteres de cloropropanóis em alimentos tem sido a liberação potencial de suas formas livres pela a ação de enzimas do sistema digestivo humano. Hamlet e $\mathrm{Sadd}^{18}$ foram os primeiros a demonstrar que ésteres de 3-MCPD e 2-MCPD presentes em pão poderiam ser hidrolisados por lipase produzida a partir de Aspergillus oryzea, liberando seus respectivos cloropropanóis.

Resultados preliminares obtidos por Seefelder e colaboradores ${ }^{21}$ utilizando um sistema modelo intestinal que simulava as condições do intestino de mamíferos também indicaram que ésteres de 3-MCPD podem ser substratos de lipases, liberando 3-MCPD. De acordo com estes autores, o uso de lipase pancreática na presença de extrato de bile suína resultou em mais de 95\% de monoésteres de 3-MCPD hidrolisados em 1 minuto, enquanto que 95\% de diésteres de 3-MCPD foram hidrolisados em 90 minutos.

Evidências adicionais de que monoésteres de 3-MCPD são hidrolisados em 3-MCPD foram demonstradas em estudos in vitro utilizando células $\mathrm{CaCo}-2$ como sistema modelo de intestino humano. ${ }^{22}$ A hidrólise observada na presença das células CaCo-2 após 24 horas foi atribuída à presença de lipases celulares, como fosfolipases A1 extra-celulares, já que lipases pancreáticas não foram utilizadas nos experimentos. Entretanto, estas evidências não foram observadas no caso de diésteres de 3-MCPD. Segundo os autores, estes compostos foram diretamente absorvidos e metabolizados pelo sistema utilizado sem serem previamente hidrolisados.

De acordo com Seefelder e colaboradores, ${ }^{21}$ os mecanismos pelos quais os ésteres de 3-MCPD são digeridos e absorvidos no corpo humano podem ser comparáveis àqueles aplicados aos acilgliceróis, uma vez que os compostos são estruturalmente similares e mostram sensibilidades compatíveis em relação à ação de lipases. In vivo, os acilgliceróis ingeridos não são absorvidos em sua forma original devido à ação de lipases do sistema digestivo. Lipases pancreáticas, com maior afinidade pelas posições $s n-1$ e $s n$-3, liberam ácidos graxos livres e glicerol a partir de 1- e 3-monoacilgliceróis (MAGs), enquanto que triacilgliceróis (TAGs) são convertidos em ácidos graxos livres e 2-MAGs. Ao atingirem a mucosa celular, os 2-MAGs são diretamente absorvidos pelos enterócitos, re-esterificados por aciltransferases celulares e então incorporados às partículas de lipoproteínas. ${ }^{23,24}$

Assumindo um metabolismo similar para os ésteres de 3-MCPD, lipases pancreáticas poderiam favorecer a hidrólise da posição $s n-1$ de 1-monoésteres e diésteres de 3-MCPD, liberando 3-MCPD livre e 2-monoésteres de 3-MCPD, respectivamente. Os 2-monoésteres de 3-MCPD seriam então diretamente absorvidos pelos enterócitos, re-esterificados e incorporados às lipoproteínas, podendo ser dessa forma depositados em tecido adiposo. ${ }^{21}$ Estas observações suportam os resultados relatados por Buhrke e colaboradores, ${ }^{22}$ que sugeriram a absorção direta de diésteres de 3-MCPD em estudos in vitro utilizando células CaCo-2.

Com base nestas informações, seria possível propor que somente os 1-monoésteres de 3-MCPD poderiam representar uma fonte adicional de exposição ao 3-MCPD. Entretanto, estudos conduzidos com roedores para avaliar a biodisponibilidade de 3-MCPD a partir de 3-MCPD-dipalmitato mostraram que a concentração de metabólitos do composto livre excretados na urina a partir da administração do éster foi de aproximadamente $70 \%$ quando comparada à concentração dos mesmos metabólitos excretados após a administração oral de doses equimolares de 3-MCPD. ${ }^{25}$ Resultados similares foram reportados por Abraham e colaboradores, ${ }^{26} \mathrm{o}$ que sugere tanto a hidrólise de diésteres in vivo quanto a significativa biodisponibilidade de 3-MCPD a partir de 3-MCPD-dipalmitato após administração oral.

\section{Toxicidade}

Poucos dados sobre o potencial tóxico dos ésteres de 3-MCPD encontram-se disponíveis na literatura até o presente. Um estudo conduzido durante 90 dias avaliou a toxicidade sub-crônica através da administração de 3-MCPD-dipalmitato em doses de 9,78 a 156,75 $\mathrm{mg} / \mathrm{kg} \mathrm{pc} / \mathrm{dia}$ a ratos de ambos os sexos. ${ }^{26} \mathrm{O}$ éster avaliado induziu alterações histopatológicas similares às observadas para o 3-MCPD. Porém, a severidade dos efeitos observados foi menos acentuada, indicando que a cinética da hidrólise pode ter um papel importante na toxicidade dos compostos. Os órgãos mais afetados foram os rins e os testículos, e a dose que provocou um aumento de $10 \%$ na incidência dessas alterações $\left(\mathrm{BMD}_{10}\right)$ foi calculada em 41,1 e 64,4 mg/kg pc/dia, 
respectivamente. $\mathrm{O}$ limite de confiança inferior desta dose $\left(\mathrm{BMDL}_{10}\right)$ foi estimado em 17,4 e 44,3 mg/kg pc/dia, respectivamente.

A toxicidade aguda de monoésteres e diésteres de 3-MCPD também foi avaliada em ratos e camundongos..$^{27,28} \mathrm{~A}$ dose que provocou a morte de $50 \%$ da população $\left(\mathrm{DL}_{50}\right)$ foi estabelecida em 2676,8 $\mathrm{mg} / \mathrm{kg}$ pc para o 3-MCPD-1-monopalmitato e acima de $5000 \mathrm{mg} / \mathrm{kg}$ pc para o 3-MCPD-dipalmitato, o que sugere baixa toxicidade dos compostos. ${ }^{28} \mathrm{O}$ estudo também confirmou que os rins e os testículos são os órgãos críticos para o desenvolvimento dos efeitos adversos.

Inibição de proliferação celular e aumento de atividade da enzima lactato desidrogenase em células epiteliais renais NRK-52E de ratos também foram observados de maneira dose-dependente após a administração de 3-MCPD-1-monopalmitato em concentrações de até $100 \mu \mathrm{g} / \mathrm{mL}$, o que sugere evidências de citotoxicidade. ${ }^{28}$ Outros autores também relataram o potencial citotóxico de monoésteres de 3-MCPD. ${ }^{27}$ Enquanto 3-MCPD-1-monopalmitato e 3-MCPD-1monoestearato mostraram toxicidade celular a $200000 \mathrm{ppm}$ com $50 \%$ de concentração inibitória (70000 e 31000 ppm, respectivamente), o 3-MCPD-2-monooleato apresentou efeito tóxico a 781 ppm (50\% de concentração inibitória, 520 ppm), indicando que o tipo de ácido graxo e sua posição na molécula podem exercer influência significativa na toxicidade celular. ${ }^{27}$ Diésteres de 3-MCPD não apresentaram evidências de citotoxicidade nas condições experimentais testadas. ${ }^{27,28}$

Por outro lado, o potencial tóxico do 3-MCPD livre tem sido bastante estudado. ${ }^{29} \mathrm{O}$ composto tem demonstrado nefrotoxicidade e efeitos adversos na reprodução em estudos conduzidos com ratos. Evidências de carcinogenicidade foram verificadas em experimentos realizados com animais após a administração de altas doses de 3-MCPD (400 ppm) por um período de dois anos. ${ }^{30}$ Entretanto, o desenvolvimento de tumores tem sido associado a um mecanismo não genotóxico. O 3-MCPD foi recentemente classificado pela Agência Internacional de Pesquisa sobre o Câncer (IARC) como possível carcinógeno humano (grupo $2 \mathrm{~B}$ ). ${ }^{12}$

De acordo com o Comitê Científico de Alimentos da Comunidade Européia $(\mathrm{SCF})^{31}$ e o Comitê Conjunto FAO/OMS de Especialistas em Aditivos Alimentares (JECFA), ${ }^{32}$ o efeito mais sensível provocado pelo 3-MCPD foi hiperplasia tubular renal e a menor dose para a qual se observou este efeito (LOEL) foi de $1,1 \mathrm{mg} / \mathrm{kg} \mathrm{pc} / \mathrm{dia}$. Com base nestas informações e considerando um fator de segurança de 500, o SCF estabeleceu uma ingestão diária tolerável (TDI) para 3-MCPD de $2 \mu \mathrm{g} / \mathrm{kg}$ pc, sendo o mesmo valor definido pelo JECFA como PMTDI. Em um estudo mais recente, Hwang e colaboradores ${ }^{33}$ estabeleceram uma $\mathrm{BMDL}_{10}$ para hiperplasia tubular renal de $0,87 \mathrm{mg} / \mathrm{kg} \mathrm{pc} / \mathrm{dia}$.

\section{ÉSTERES DE 3-MCPD EM ALIMENTOS}

\section{Ocorrência}

A ocorrência de formas ligadas de cloropropanóis em alimentos foi levantada pela primeira vez por pesquisadores do Instituto de Tecnologia Química de Praga, na República Tcheca, por volta de 1980. ${ }^{15,34,35}$ Ésteres de 3-MCPD e 1,3-DCP com ácidos graxos foram identificados em proteína vegetal hidrolisada e em sistemas modelos compostos por ácido clorídrico e TAGs. Estes ésteres também foram encontrados em óleo de colza espanhol adulterado ${ }^{36}$ e em leite de cabra, ${ }^{37}$ mas nenhum outro estudo foi direcionado a esta questão até Svejkovská e colaboradores ${ }^{7}$ reportarem, mais recentemente, a presença de altos níveis de ésteres de 3-MCPD em diversos alimentos processados e ingredientes alimentícios.

De acordo com os autores, concentrações entre 140 e $6100 \mu \mathrm{g} /$ $\mathrm{kg}$ foram encontradas em biscoito salgado, doughnuts (ou donuts), crispbread, malte, arenque em conserva e batata frita, sendo que os níveis de ésteres de 3-MCPD excediam de 5 a 396 vezes os níveis encontrados para a sua forma livre. ${ }^{7}$ Esta descoberta desencadeou uma série de investigações sobre a ocorrência de ésteres de 3-MCPD em outros alimentos e ingredientes, incluindo pão, óleos vegetais, café, substitutos de café e malte, e até mesmo em leite materno humano. ${ }^{18,38-41}$

Entretanto, os resultados reportados por Zelinková e colaboradores, ${ }^{38}$ mostrando a ocorrência de ésteres de 3-MCPD em óleos vegetais refinados em concentrações de até $2462 \mu \mathrm{g} / \mathrm{kg}$, foram os que geraram maior impacto e repercussão. Estudos posteriores confirmaram estas informações e mostraram concentrações ainda mais elevadas em óleo de palma refinado e gorduras para fritura. ${ }^{42,43}$ Em função destas observações, grande parte das pesquisas sobre os ésteres de 3-MCPD vem sendo conduzida com estes produtos.

A contaminação de alimentos devido ao uso de gorduras e óleos refinados em suas formulações ou processos também foi confirmada em diversos estudos, incluindo produtos como creamer para café, chantilly, caldo em cubo, fórmulas infantis e alimentos fritos. ${ }^{8,19,42,44,45}$ A Tabela 2 mostra as concentrações totais de ésteres de 3-MCPD reportadas em alimentos e ingredientes alimentícios, segundo os estudos disponíveis na literatura.

Considerando que a estrutura dos ésteres de 3-MCPD pode exercer um papel determinante nos mecanismos de hidrólise e absorção, é muito importante que suas contribuições relativas como monoésteres e diésteres sejam avaliadas. ${ }^{46}$ Diversos estudos têm demonstrado que os níveis de diésteres são superiores aos de monoésteres e que as espécies predominantes dos compostos variam em função do tipo de amostra. ${ }^{19,21,38,41,47,48}$ Em óleo de palma, por exemplo, Yamazaki e colaboradores ${ }^{48}$ reportaram $12940 \mu \mathrm{g} / \mathrm{kg}$ de diésteres e $1460 \mu \mathrm{g} /$ $\mathrm{kg}$ de monoésteres de 3-MCPD. Os principais tipos de diésteres encontrados foram 3-MCPD-palmitato-oleato, 3-MCPD-dipalmitato e 3-MCPD-dioleato.

\section{Formação}

Em alimentos processados, a formação de ésteres de 3-MCPD deve ocorrer pela reação entre lipídeos e cloreto de sódio, assim como observado para a forma livre do composto. ${ }^{49,50}$ Estudos realizados por Svejkovská e colaboradores ${ }^{51}$ utilizando sistemas modelos aquecidos a $100{ }^{\circ} \mathrm{C}$ durante 30 minutos mostraram que a formação de ésteres de 3-MCPD foi diretamente proporcional à concentração de lipídeos e de sal, sendo que as maiores concentrações foram verificadas nos experimentos contendo $20 \%$ de água. Os autores observaram também que o aumento da temperatura de 100 a $230{ }^{\circ} \mathrm{C}$ provocou, simultaneamente, a formação e a decomposição dos compostos, e que altas temperaturas associadas a longos tempos de aquecimento resultaram nas maiores concentrações de ésteres.

Em óleos, a formação de ésteres de 3-MCPD tem sido associada à etapa de refino, ${ }^{38,52}$ que tem como objetivo a remoção de impurezas como ácidos graxos livres, fosfolipídeos, produtos de oxidação e pigmentos, entre outros, as quais poderiam afetar a qualidade do produto final. Esse processo pode ser feito: 1) fisicamente, no qual os compostos indesejáveis são removidos por destilação através de um processo baseado na grande diferença de volatilidade entre os ácidos graxos livres e o óleo neutro; ${ }^{53}$ ou 2) quimicamente, em que os ácidos graxos livres são neutralizados por uma base (soda cáustica) dando origem a um sabão que é removido por separação de fase. ${ }^{52}$

O refino físico é geralmente aplicado a óleos com elevada acidez, como o óleo de palma, nos quais o refino químico poderia ocasionar grandes perdas de óleo neutro.$^{54} \mathrm{Em}$ algumas regiões brasileiras, como na Bahia, o óleo de palma (ou óleo de dendê, como é conhecido no país), também é consumido na sua forma bruta, ou seja, sem passar pelo processo de refino. O óleo bruto contém elevadas concentrações 
Tabela 2. Concentração total de ésteres de 3-MCPD em alimentos e ingredientes alimentícios

\begin{tabular}{|c|c|c|c|}
\hline Alimento/Ingrediente & $\begin{array}{l}\text { Média } \\
(\mu g / k g)\end{array}$ & $\begin{array}{c}\text { Mín - Máx } \\
(\mu \mathrm{g} / \mathrm{kg})\end{array}$ & Referência \\
\hline Biscoito & - & $50-865$ & $7,83,104$ \\
\hline Cereal matinal & - & nd - 43 & 83,104 \\
\hline Noodles & 53 & nd -210 & 104 \\
\hline Pão & - & nd -230 & $18,83,104$ \\
\hline Pão (miolo) & 4,9 & - & 18 \\
\hline Pão (casca) & 547 & - & 18 \\
\hline Pão (torrado) & 160 & - & 18 \\
\hline Crispbread & 420 & - & 7 \\
\hline Café torrado & - & nd -390 & $7,39,83$ \\
\hline Substitutos de café & 721 & $145-1184$ & 40 \\
\hline Malte & - & $4-650$ & 7,40 \\
\hline Arenque em conserva & 280 & - & 7 \\
\hline Amêndoa e amendoim & - & $433-500$ & 38 \\
\hline Leite materno (humano) & 35,5 & nd - 76 & 41 \\
\hline Gordura animal (não refinada) & - & $<100-300$ & 43 \\
\hline Óleo vegetal (não refinado) & - & $<100-400$ & $38,42,43$ \\
\hline Óleo vegetal refinado & - & $<100-19000$ & $20,42,43$ \\
\hline Girassol & - & $100-2100$ & $20,38,104$ \\
\hline Milho & - & $120-470$ & $20,38,83$ \\
\hline Canola & - & $<100-1000$ & $20,38,83,104$ \\
\hline Soja & - & $<100-1234$ & 20,38 \\
\hline Oliva & - & $<300-2462$ & $20,38,83$ \\
\hline Oliva (bagaço) & - & $1047-2332$ & 38 \\
\hline Amendoim & - & $100-900$ & 20,83 \\
\hline Semente de uva & 1200 & $390-2500$ & 83 \\
\hline Coco & - & $200-1694$ & 20,42 \\
\hline Gergelim & 345 & - & 104 \\
\hline Palma & - & $1100-14400$ & $20,42,48$ \\
\hline Palmiste & - & $200-1400$ & 20,42 \\
\hline Margarina & - & $400-4500$ & $43^{\mathrm{a}}, 104$ \\
\hline Maionese & - & $<150-1040$ & $43^{\mathrm{a}}$ \\
\hline Gordura para fritura & - & $500-5200$ & $43^{\mathrm{a}}$ \\
\hline Calda e recheio de biscoitos & - & $<100-7500$ & $43^{\mathrm{a}}$ \\
\hline Creamer para café & 385 & $130-730$ & 42 \\
\hline Chantilly & 359 & $50-730$ & 42 \\
\hline Caldo em cubo & 502 & $380-670$ & 42 \\
\hline Sopa e molho (em pó) & $231-660$ & - & 104 \\
\hline Fórmula infantil & - & $62-3300^{a}$ & $19,43^{\mathrm{a}}$ \\
\hline Batata pré-frita & - & $27-64$ & 44,45 \\
\hline Batata frita & - & $37-6100$ & $7,44,45,83$ \\
\hline Batata chips & - & $22-2201$ & $7,44,45,83$ \\
\hline Frango empanado & - & $9-160$ & 83 \\
\hline Doughnut & 1210 & - & 7 \\
\hline
\end{tabular}

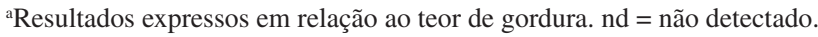

de vitamina A, a qual desempenha um papel de extrema importância durante o desenvolvimento fetal..$^{55}$

A formação dos ésteres de 3-MCPD durante o refino ocorre na etapa de desodorização, onde temperaturas acima de $200{ }^{\circ} \mathrm{C}$ são utilizadas..$^{56,57}$ Tem sido demonstrado que o tipo de refino (químico ou físico) e as condições utilizadas (tempo e temperatura) parecem não exercer influência significativa nos níveis finais dos compostos. ${ }^{57}$

Em alimentos fritos ou ricos em gordura, a presença de ésteres de 3-MCPD tem sido atribuída ao uso do óleo contaminado no processo de fritura ou na formulação dos produtos. ${ }^{44,58}$ Entretanto, a formação intrínseca também pode ser significativa em alimentos que contêm precursores potenciais de ésteres de 3-MCPD e que são submetidos a altas temperaturas durante seu processamento. ${ }^{59}$

O leite materno foi o único alimento avaliado até o presente que pode ser considerado naturalmente contaminado com ésteres de 3-MCPD. Estes resultados indicam que ésteres de 3-MCPD podem ser absorvidos diretamente na sua forma ligada ou que 2-monoésteres de 3-MCPD liberados pela hidrólise de diésteres de 3-MCPD podem ser absorvidos, re-esterificados e depositados nas glândulas mamárias. ${ }^{46}$

\section{Mecanismos}

Os principais mecanismos envolvidos na formação de cloropropanóis e de seus ésteres foram inicialmente estudados por Collier e colaboradores $^{60}$ e recentemente revisados por alguns autores..$^{59,61,62}$ De acordo com Rahn e Yaylayan, ${ }^{61}$ quatro mecanismos podem ser propostos para explicar a formação destes compostos. Dois deles envolvem o ataque nucleofílico direto dos átomos de carbono da estrutura do glicerol na molécula dos acilgliceróis pelo íon cloreto, enquanto os outros dois envolvem a formação de compostos reativos intermediários a partir dos acilgliceróis, como um íon aciloxônio ou um epóxido, antes do ataque nucleofílico pelo íon cloreto. A Figura 1 apresenta um esquema resumido dos mecanismos propostos.

(a)

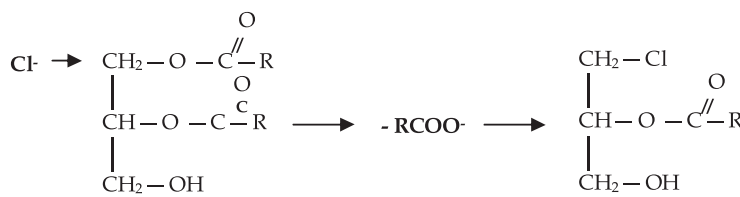

(b)

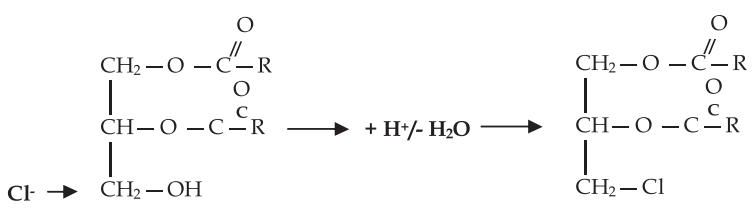

(c)

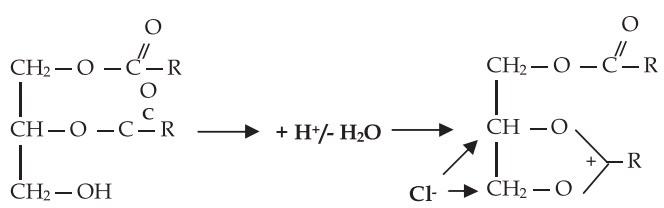

(d)

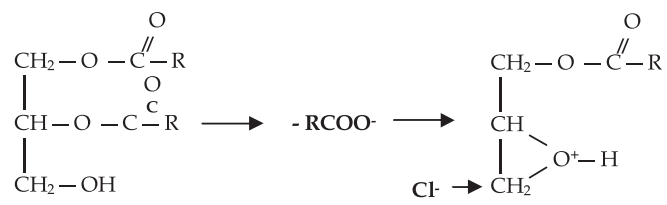

Figura 1. Resumo dos mecanismos propostos para a formação de ésteres de 3-MCPD de acordo com Rahn e Yaylayan ${ }^{61}$ (a: ataque nucleofílico direto na posição sn-1; b: ataque nucleofílico direto na posição sn-3; c: ataque nucleofílico do íon aciloxônio; d: ataque nucleofílico do epóxido)

$\mathrm{O}$ ataque nucleofílico direto pode ocorrer nas posições $s n-1$ e $s n-3$, a depender do impedimento estérico dos átomos de carbono na molécula, deslocando um grupo éster ou um grupo hidroxila e formando ésteres de 1- ou 3-MCPD. Em meio aquoso, a reação deve proceder mais rapidamente a partir de diacilgliceróis (DAGs) e MAGs na presença de ácido, deslocando preferencialmente um grupo hidroxila. ${ }^{61}$ Estudos conduzidos por Svejkovská e colaboradores ${ }^{51}$ mostraram a substituição nucleofílica direta de 1-monopalmitina no grupo hidroxila $\left(100{ }^{\circ} \mathrm{C}, 30\right.$ minutos), sendo que as maiores 
concentrações de ésteres de 3-MCPD foram obtidas a partir deste MAG, seguido por 1,3-dipalmitina e tripalmitina.

Evidências do envolvimento de um íon aciloxônio na reação foram inicialmente levantadas por Collier e colaboradores. ${ }^{60} \mathrm{Em}$ meio aquoso, na presença de ácido, foi demonstrado que íons aciloxônios eram formados a partir de DAGs originados após a hidrólise de TAGs ${ }^{60}$ Entretanto, Rahn e Yaylayan ${ }^{63}$ mostraram mais recentemente, por espectroscopia em infravermelho por transformada de Fourier, que íons aciloxônios podem ser formados em meio não aquoso diretamente a partir de MAGs, DAGs e TAGs, através de ataque nucleofílico interno da carbonila do grupo éster. O deslocamento do grupo éster (no caso de DAGs e TAGs) levaria à formação de um íon aciloxônio que posteriormente poderia ser convertido em diésteres de 2- e 3-MCPD, enquanto que o deslocamento do grupo hidroxila (no caso de DAGs e MAGs) levaria à formação de um íon aciloxônio que posteriormente poderia gerar monoésteres de 2- e 3-MCPD.

A formação de ésteres de 3-MCPD por meio de epóxidos tem sido demonstrada a partir de ésteres de glicidol. Nesse caso, a substituição nucleofílica pelo íon cloreto pode ocorrer no carbono estericamente menos impedido provocando a abertura do anel do epóxido para formar exclusivamente 1-monoésteres de 3-MCPD. ${ }^{61}$ MAGs e DAGs têm sido considerados os principais precursores dos ésteres de glicidol, sendo estes últimos originados por ataque nucleofílico interno de DAGs ou a partir do íon aciloxônio gerado pelo deslocamento do grupo hidroxila. ${ }^{61,64}$

\section{Precursores}

Em relação aos precursores lipídicos, os altos níveis de ésteres de 3-MCPD encontrados em óleos obtidos a partir de frutos, como palma e oliva, levantaram as primeiras suspeitas de que DAGs seriam os principais precursores da reação, tendo em vista a contribuição desta classe de lipídeos em comparação a outros tipos de matéria-prima. ${ }^{38,56} \mathrm{O}$ óleo de palma, por exemplo, possui em sua composição 88-95\% de TAGs, $4-12 \%$ de DAGs e $0,2-0,35 \%$ de MAGs, sendo que o seu teor de acilgliceróis parciais (MAGs e DAGs) está diretamente relacionado ao tempo decorrente entre a colheita dos frutos e seu processamento, por ser resultante da degradação dos TAGs através da ação de uma enzima hidrolítica presente no exterior do fruto. ${ }^{53,65}$

Entretanto, tentativas de correlacionar os níveis de DAGs e ésteres de 3-MCPD mostraram resultados controversos ${ }^{57,66,67}$ e estudos mais recentes conduzidos com sistemas modelos simulando o processo de desodorização de óleo de palma demonstraram que, embora os DAGs possam interagir com íons cloreto e resultar na formação de ésteres de 3-MCPD, esta não deve ser a rota predominante da reação. ${ }^{68}$

Destaillats e colaboradores ${ }^{68}$ também verificaram que TAGs foram os substratos mais reativos na formação de diésteres de 3-MCPD em temperaturas acima de $150{ }^{\circ} \mathrm{C}$. Considerando que o teor de TAGs corresponde a aproximadamente $90 \%$ dos lipídeos totais de óleos e que diésteres de 3-MCPD têm sido reportados em concentrações significativamente superiores às de monoésteres, estes resultados sugerem que esta pode ser a principal via de formação de ésteres de 3-MCPD em óleos.

Em relação à fonte de cloreto, as hipóteses levantadas inicialmente eram de que o íon pudesse estar presente no óleo ou no vapor utilizado no processo de desodorização. Entretanto, investigações sobre o teor de cloreto tanto em óleos (antes e após a desodorização) quanto no vapor não encontraram correlação com a formação de ésteres de 3-MCPD. ${ }^{52,56,57}$ Novas evidências sobre a origem do cloreto mostraram que diversas espécies de cloro orgânico e inorgânico ligadas covalentemente, resultantes do metabolismo endógeno da planta e da contaminação ambiental, podem estar presentes no óleo de palma bruto. ${ }^{69}$ Experimentos in vitro indicaram uma alta correlação entre a decomposição térmica de compostos clorados orgânicos/inorgânicos e a formação de diésteres de 3-MCPD, e mostraram que o íon cloreto envolvido na reação pode ter sido proveniente do ácido clorídrico gerado pela degradação destes compostos. ${ }^{68,69}$

\section{Métodos analíticos}

Muitos esforços têm sido direcionados ao desenvolvimento de métodos analíticos para a determinação de ésteres de 3-MCPD. Progressos significativos foram obtidos especialmente nos últimos quatro anos, como mostrado em uma detalhada revisão recentemente publicada por Crews e colaboradores. ${ }^{70}$ As estratégias analíticas propostas para a determinação destes compostos envolvem: 1) análise indireta, na qual a concentração total dos ésteres de 3-MCPD é medida como 3-MCPD livre, obtido após um procedimento de hidrólise/ metanólise; ${ }^{18,21,37,38,71,72-75}$ e 2) análise direta, na qual os ésteres de 3-MCPD são identificados individualmente. ${ }^{19,38,41,47,48,76-78}$

\section{Determinação indireta de ésteres de 3-MCPD}

De maneira geral, os métodos baseados na análise indireta de ésteres de 3-MCPD incluem a adição de padrão interno à amostra, hidrólise/metanólise, neutralização, remoção de ésteres metílicos de ácidos graxos (FAMEs) por salting-out, derivatização do 3-MCPD liberado com ácido fenilborônico (PBA) e análise por cromatografia gasosa acoplada à espectrometria de massas (GC/MS). A principal vantagem destes métodos é a necessidade de um número pequeno de padrões analíticos, enquanto que as principais desvantagens são a impossibilidade de identificação dos tipos de ésteres presentes e o grande número de etapas envolvidas no preparo da amostra, o que pode tornar o procedimento longo e susceptível a erros. ${ }^{70}$

A metanólise catalisada por ácido ou base (transesterificação química) tem sido utilizada na maior parte dos métodos descritos na literatura para a liberação de 3-MCPD a partir de seus ésteres. . $11,37,38,71,72,73^{-1}$

O procedimento de metanólise catalisada por ácido foi inicialmente proposto por Cerbulis e colaboradores ${ }^{37}$ e adaptado por Divinová e colaboradores. ${ }^{71}$ De acordo com os autores, a liberação de 3-MCPD ocorre em 16 horas na presença de uma solução de ácido sulfúrico em metanol. Soluções de bicarbonato de sódio e cloreto de sódio são utilizadas para as etapas de neutralização e salting-out, respectivamente. ${ }^{37,71}$ Diversas modificações deste procedimento já foram propostas, incluindo a utilização de sais livres de cloreto para o salting-out e de heptafluorobutirilimidazol (HFBI) como agente de derivatização..$^{21,79}$ Estes métodos apresentam boa robustez, mas a principal desvantagem é o tempo requerido para a etapa de transesterificação.

A metanólise catalisada por base foi inicialmente sugerida por Weißhaar. ${ }^{72}$ Neste procedimento, o 3-MCPD é liberado de seus ésteres em 10 minutos na presença de uma solução de metóxido de sódio em metanol. Soluções de ácido acético glacial e cloreto de sódio são utilizadas para as etapas de neutralização e salting-out, respectivamente. $\mathrm{O}$ método foi validado em um estudo colaborativo e então adotado pela Sociedade Alemã de Pesquisa de Óleos e Gorduras como DGF C-III 18 (09) ${ }^{80,81}$ A significativa redução do tempo de transesterificação foi apontada como a sua principal vantagem.

O desempenho de métodos indiretos baseados em transesterificação química foi avaliado em dois ensaios de proficiência realizados com óleo de palma refinado..$^{70,82} \mathrm{Em}$ ambos os casos, uma grande variação foi observada nos resultados submetidos pelos laboratórios participantes, indicando o impacto do método utilizado. Enquanto os procedimentos baseados em transesterificação ácida produziram resultados satisfatórios, valores superestimados foram observados para os métodos que empregavam metanólise alcalina e salting-out com solução de cloreto de sódio.

As discrepâncias observadas foram atribuídas à presença de ésteres de glicidol em óleos refinados que, em condições alcalinas, 
poderiam ser hidrolisados à glicidol. A superestimação dos resultados seria conseqüência da formação de 3-MCPD durante a análise a partir do glicidol na presença de cloreto. ${ }^{64}$ Este método passou então por diversas modificações, incluindo a realização de um pré-tratamento com solução de ácido sulfúrico em propanol antes da transesterificação para destruição dos ésteres de glicidol e a utilização de sais livres de cloreto para o salting-out, mas seu desempenho ainda tem sido questionado. ${ }^{70}$

Métodos baseados na hidrólise enzimática dos ésteres de 3-MCPD são apresentados como alternativas aos procedimentos que utilizam a transesterificação química. O uso de lipase de diversas fontes tem sido avaliado, entre elas aquelas obtidas de culturas de Aspergillus oryzae, Candida rugosa e Candida antarctica.$^{18,74,75}$ Além da redução do tempo de análise, a principal vantagem destacada é a manutenção da integridade das moléculas, já que nas condições de hidrólise a interconversão entre o 3-MCPD e o glicidol não é favorecida. A adição de íons brometo antes da etapa de derivatização com o PBA leva à formação de 3-MBPD (3-monobromopropano-1,2-diol) a partir do glicidol liberado, impedindo a formação de 3-MCPD pela reação com os íons cloreto disponíveis. Apesar das vantagens destacadas, deve ser considerada a possibilidade da formação de MCPDs, catalisada por lipase, a partir de triglicerídeos contendo ácidos graxos de cadeia curta, conforme exposto por Hamlet e Sadd. ${ }^{18}$

Conforme destacado anteriormente, informações relacionadas à natureza dos compostos individuais não podem ser obtidas na análise indireta de ésteres de 3-MCPD. De forma a suprir parcialmente esta deficiência, Seefelder e colaboradores ${ }^{21}$ propuseram a separação de monoésteres e de diésteres por extração em fase sólida (SPE) em cartuchos de aminopropil antes da etapa de transesterificação, permitindo assim a identificação e quantificação das frações totais de cada espécie.

\section{Determinação direta de ésteres de 3-MCPD}

As discussões em torno da confiabilidade dos resultados gerados pelos procedimentos baseados em transesterificação/hidrólise motivaram o desenvolvimento de métodos analíticos diretos, de forma a evitar a necessidade de reações químicas durante o preparo da amostra. Entre as principais vantagens destes procedimentos destacam-se a maior simplicidade da análise e o maior detalhamento das informações obtidas, ao passo que a forte similaridade entre os analitos e os constituintes da matriz (em particular MAGs e DAGs), a necessidade de um grande número de padrões analíticos e a limitada aplicação como ensaios de rotina são apontadas como suas principais desvantagens. ${ }^{70}$

Os métodos de análise direta foram inicialmente baseados na separação prévia de monoésteres e diésteres por cromatografia em camada delgada ou em coluna aberta de sílica gel, seguida pela análise dos compostos por GC-MS. 19,38,41 Estudos mais recentes têm mostrado o grande potencial da cromatografia líquida de alta eficiência acoplada à espectrometria de massas (LC-MS) para a determinação dos compostos individuais, empregando analisadores de massas do tipo time of flight (TOF), orbitrap e triploquadrupolo (MS/MS). ${ }^{70}$ Alguns autores propõem a injeção direta da amostra após diluição em solvente apropriado enquanto outros sugerem a utilização de SPE em cartuchos de sílica, C18 e aminopropil para limpeza do extrato e separação das frações correspondentes a monoésteres e diésteres. ${ }^{47,48,76-78}$

$\mathrm{O}$ desempenho de métodos diretos ainda não foi avaliado em ensaios de proficiência. Entretanto, alguns autores têm comparado os resultados obtidos por estes métodos àqueles gerados pelos procedimentos indiretos. ${ }^{47,76}$ Quando a comparação foi feita considerando dados obtidos por transesterificação ácida, boa concordância entre os resultados foi observada. ${ }^{47}$ Já quando a comparação envolveu o procedimento de metanólise alcalina descrito por Weißhaar, ${ }^{72}$ resultados superestimados foram consistentemente reportados para o método indireto, o que mais uma vez indica o impacto da técnica analítica na determinação da concentração dos compostos. ${ }^{76}$

\section{Estimativa de ingestão e avaliação do risco}

Estudos preliminares têm estimado a ingestão de 3-MCPD a partir de seus ésteres, considerando a hidrólise completa destes compostos. Com base nesse princípio, o Instituto Federal Alemão para Avaliação do Risco (BfR $)^{8}$ estimou que a ingestão de 3-MCPD para adultos através do consumo de óleos e gorduras vegetais poderia chegar a até cinco vezes o valor da PMTDI de $2 \mu \mathrm{g} / \mathrm{kg}$ pc estabelecida pelo JECFA, considerando o nível mais alto de ésteres de 3-MCPD encontrado nesses produtos. Entretanto, um estudo conduzido em Hong Kong mostrou que a ingestão destes compostos corresponde de 0,7 a $26 \%$ da PMTDI, considerando tanto grandes e médios consumidores quanto o consumo de alimentos processados e de óleos e gorduras. ${ }^{83}$

Para crianças alimentadas com fórmulas infantis, o BfR ${ }^{8}$ estimou que a ingestão de 3-MCPD poderia corresponder de 3,6 a 20 vezes o valor da PMTDI, utilizando os níveis mínimo e máximo de ésteres de 3-MCPD encontrados nas amostras. Com base no mesmo princípio, Zelinková e colaboradores ${ }^{19}$ estimaram que a ingestão de 3-MCPD devido à presença de seus ésteres em fórmulas infantis poderia chegar a até 8,2 vezes o valor da PMTDI.

Considerando a alta biodisponibilidade do 3-MCPD verificada em alguns estudos após administração oral de 3-MCPD-dipalmitato ${ }^{25,26}$ e a indicação de que diésteres estão presentes em concentrações superiores às de monoésteres, ${ }^{19,21,38,41}$ estes dados iniciais sugerem que a ocorrência de ésteres de 3-MCPD em alimentos pode estar associada a riscos significativos à saúde humana.

Desde 2009, o Comitê do Codex sobre Contaminantes em Alimentos (CCCF) têm solicitado uma avaliação toxicológica completa dos ésteres de 3-MCPD ao JECFA. ${ }^{84-87}$ Entretanto, como informações importantes estão sendo recentemente disponibilizadas, o JECFA ainda não fez a solicitação dos dados. Diante de tais evidências, é altamente recomendável que estratégias de mitigação sejam desenvolvidas de forma a diminuir a exposição dos consumidores a estes compostos.

\section{Mitigação}

Os estudos relacionados ao desenvolvimento de estratégias de mitigação de ésteres de 3-MCPD têm sido focados na redução da contaminação de óleos e gorduras, especialmente de óleo de palma. De maneira geral, três estratégias independentes têm sido investigadas: 1) remoção dos precursores potenciais; 2) modificações dos parâmetros de processamento; e 3) degradação ou remoção dos compostos do produto final. ${ }^{59,66}$

Considerando a remoção dos possíveis precursores, resultados promissores têm sido obtidos com a inclusão de uma etapa de lavagem do óleo bruto com solução aquosa contendo etanol, antes da desodorização. ${ }^{66,88}$ Este processo foi associado à remoção de compostos clorados orgânicos e mostrou reduções de aproximadamente $30 \%$ nos níveis finais de ésteres de 3-MCPD. A lavagem da polpa da fruta da palma antes da extração do óleo produziu resultados ainda mais satisfatórios, em torno de $95 \%$ de redução de diésteres de 3-MCPD. ${ }^{88}$

Em relação ao processo de desodorização (que geralmente é realizado de 230 a $260{ }^{\circ} \mathrm{C}$ ), pouco sucesso deve ser conseguido através de modificações no perfil de tempo/temperatura desta etapa. ${ }^{62}$ Além de Hrncirik e Van Duijn ${ }^{57}$ verificarem que os níveis de ésteres de 3-MCPD em óleo de palma refinado foram independentes das condições de desodorização, Franke e colaboradores, ${ }^{56}$ assim como Destaillats e 
colaboradores ${ }^{68}$ mostraram que a formação dos compostos pode ocorrer inclusive a $200{ }^{\circ} \mathrm{C}$.

Por outro lado, a adição de $1 \%$ de glicerol ou etanol ao óleo antes da desodorização resultou em reduções de 25 a $35 \% .{ }^{88}$ Alterações em outras etapas do refino, incluindo degomagem, neutralização e clarificação, também podem reduzir a capacidade de formação de ésteres de 3-MCPD. ${ }^{52,67,89,90}$ Bons resultados foram obtidos após degomagem aquosa e clarificação com silicato de magnésio sintético ${ }^{67}$ ou argila natural. ${ }^{89}$

Estudos sobre a decomposição de ésteres de 3-MCPD em sistemas modelos simulando alimentos processados demonstraram que estes compostos são instáveis e se decompõe sob aquecimento. A taxa de decomposição do 3-MCPD-dipalmitato aumentou rapidamente com o aumento da temperatura de 100 a $230{ }^{\circ} \mathrm{C} .{ }^{51} \mathrm{~A}$ remoção enzimática de ésteres de 3-MCPD no produto final também foi demonstrada em sistemas modelos através da utilização de lipase de Cândida antarctica para a liberação de 3-MCPD e de sua posterior conversão a glicerol pela ação de diferentes enzimas. ${ }^{91} \mathrm{O}$ emprego de adsorventes inorgânicos para a remoção dos compostos do óleo refinado não mostrou resultados significativos. ${ }^{92}$

\section{ÉSTERES DE GLICIDOL}

O atual interesse nos ésteres de glicidol surgiu devido às discrepâncias observadas entre os resultados obtidos por meio de métodos de análise indiretos, conforme discutido anteriormente na secção 4.3.1. Estes ésteres correspondem às formas ligadas do glicidol, um composto orgânico caracterizado estruturalmente por uma molécula de glicerol contendo os grupos funcionais epóxido e álcool, nas quais a hidroxila se encontra esterificada com um ácido graxo (Figura 2).<smiles>OCC1COC1</smiles>

Glicidol

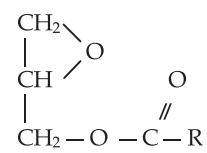

Éster de glicidol
Figura 2. Estrutura química do glicidol e seus ésteres. $R=$ grupo alquila

Esta descoberta também despertou grande preocupação do ponto de vista toxicológico, já que estes compostos podem representar uma fonte importante de glicidol na dieta caso sejam hidrolisados durante o processo digestivo. ${ }^{11} \mathrm{~A}$ exposição ao glicidol é preocupante devido às suas propriedades genotóxica e carcinogênica verificadas em experimentos com animais. ${ }^{93,94}$ Além disso, o glicidol é classificado pela IARC como uma substância provavelmente carcinogênica para seres humanos (grupo 2A) ${ }^{95}$

Estudos recentemente conduzidos com sistemas modelos gastrointestinais demonstraram que os ésteres de glicidol podem ser substratos de lipases e, consequentemente, liberar glicidol durante a digestão, porém esta etapa parece depender diretamente do $\mathrm{pH}$ do meio. ${ }^{96}$ No entanto, ainda não existem dados experimentais relacionados à biodisponibilidade do composto livre quando ingerido na forma esterificada. ${ }^{97}$

Os ésteres de glicidol têm sido encontrados em quantidades relativamente elevadas em óleos vegetais e gorduras refinadas, assim como na maioria dos produtos contendo estes ingredientes, incluindo fórmulas infantis. ${ }^{29} \mathrm{~A}$ Tabela 3 apresenta as concentrações reportadas nos estudos disponíveis até o presente. O óleo de palma refinado está entre os produtos que contêm os níveis mais elevados, podendo apresentar concentrações de até $10000 \mu \mathrm{g} / \mathrm{kg} .{ }^{70}$

De acordo com a literatura, a formação destes contaminantes também ocorre durante o refino de óleos e gorduras vegetais. Entretanto,
Tabela 3. Concentração de ésteres de glicidol em alimentos e ingredientes (adaptado de Crews e colaboradores) $^{70}$

\begin{tabular}{lcl}
\hline Alimento/Ingrediente & Mín - Máx $(\mu \mathrm{g} / \mathrm{kg})$ & Referência \\
\hline Gordura animal (não refinada) & $<100$ & 43 \\
Óleo vegetal não refinado & $<100$ & 20,43 \\
Óleo vegetal refinado & $<150-4100$ & $20,43,76$ \\
Óleo de palma & $300-10000$ & 20,105 \\
Oleína de palma & $400-15600$ & 76 \\
Óleo de cozimento & $3000-28000$ & 105 \\
Gordura para fritura & $<150-10700$ & 43 \\
Margarina & $<150-5000$ & $43^{\mathrm{a}}$ \\
Maionese & $<150-330$ & $43^{\mathrm{a}}$ \\
Fórmula infantil & $<150-3000$ & $43^{\mathrm{a}}$ \\
\hline
\end{tabular}

${ }^{a}$ Resultados expressos em relação ao teor de gordura.

ao contrário dos ésteres de 3-MCPD, a reação parece ser fortemente influenciada pelas condições de desodorização e pela concentração de DAGs. ${ }^{52,57,98,99}$

Em relação às condições de desodorização, Craft e colaboradores $^{98}$ observaram que a formação de ésteres de glicidol em óleo de palma é mínima para temperaturas abaixo de $200{ }^{\circ} \mathrm{C}$ e aumenta significativamente para tratamentos realizados a $220-230{ }^{\circ} \mathrm{C}$ durante 2 horas. Concentrações ainda mais elevadas foram associadas a temperaturas acima de $270{ }^{\circ} \mathrm{C}$ e aos longos períodos (3-6 h) utilizados na etapa de desodorização. Resultados similares foram reportados em outros estudos..$^{52,57}$

Quanto à concentração de DAGs, alguns trabalhos sugerem que a formação dos ésteres de glicidol aumenta exponencialmente quando a concentração destes lipídeos excede 3-4\% a concentração de lipídeos totais e que óleos contendo altos teores de DAGs (87\%) podem apresentar concentrações 10 vezes mais elevadas de ésteres quando comparados a óleos com baixos teores destes lipídeos (3.96.8\%). ${ }^{98,100}$ Estudos conduzidos com MAGs, DAGs e TAGs puros submetidos às condições de refino em temperaturas superiores a 200 ${ }^{\circ} \mathrm{C}$ confirmaram que os ésteres de glicidol são formados basicamente a partir de DAGs e MAGs. ${ }^{99}$

A formação dos compostos a partir de DAGs ocorre através de um rearranjo intramolecular, o qual é seguido por uma consequente eliminação dos ácidos graxos quando o óleo é submetido a altas temperaturas. A eliminação do ácido graxo pode ser iniciada através da abstração do próton proveniente do grupo hidroxila pelo grupo carboxila vicinal. $\mathrm{O}$ intermediário aciloxônio gerado é então rearranjado através de migração das cargas, resultando na liberação do ácido graxo. O anel oxirano é então formado através de uma reação nucleofílica do grupo alcóxido. Teoricamente, esta reação pode ocorrer para ambos 1,2- e 1,3-DAGs. ${ }^{99}$

A participação dos MAGs na reação é consideravelmente limitada, devido aos seus baixos teores e alta volatilidade. ${ }^{99}$ Entretanto, alguns estudos têm levantado a hipótese de que os ésteres de glicidol podem ser formados através da desidratação térmica do diol vicinal destes acilgliceróis. ${ }^{59}$ Outra hipótese para a formação de ésteres de glicidol envolve a reação a partir de monoésteres de 3-MCPD, mas esta rota também não deve contribuir de maneira significativa ao total de ésteres de glicidol formado durante o refino de óleos, pois estes compostos estão presentes em baixas concentrações. ${ }^{99}$

Como resultado do aquecimento de DAGs em temperaturas acima de $140{ }^{\circ} \mathrm{C}$, Destaillats e colaboradores ${ }^{99}$ detectaram pela primeira vez a presença de isômeros de ésteres de glicidol, os quais foram posteriormente identificados como ésteres de oxopropila através de análises por espectrometria de massas. Segundo os autores, estes ésteres de 
oxopropila podem ser formados a partir dos DAGs através de um rearranjo intramolecular, porém essa reação ocorre com a perda de ácidos graxos e a formação de um enol intermediário, o qual é submetido posteriormente a uma reação de tautomerismo. É importante mencionar que a formação dos ésteres de oxopropila foi verificada mesmo em baixas temperaturas $\left(150^{\circ} \mathrm{C}\right)$ e teve sua estabilização em torno de $200{ }^{\circ} \mathrm{C}$, temperatura na qual a taxa de formação dos ésteres de glicidol apresenta aumento expressivo.

Assim como para os ésteres de 3-MCPD, métodos diretos e indiretos têm sido propostos para a determinação de ésteres de glicidol. ${ }^{70} \mathrm{Na}$ análise direta, a amostra pode ser simplesmente diluída em solvente apropriado ou preparada por SPE de duplo estágio em cartuchos de sílica e de C18 antes da análise por LC-MS.76,77,100,101

Para o método indireto, duas alternativas têm sido sugeridas. Uma das opções é o procedimento baseado em transesterificação alcalina conforme descrito anteriormente em 4.3.1, utilizando duas análises independentes: uma que determina a soma de ésteres de 3-MCPD e de glicidol utilizando cloreto de sódio para o salting-out, e outra que determina somente ésteres de 3-MCPD, através da aplicação de um pré-tratamento ácido para destruição dos ésteres de glicidol. A diferença entre estas duas determinações permite o cálculo da concentração total dos compostos. ${ }^{70}$ Esta estratégia tem recebido diversas críticas quanto à sua confiabilidade, especialmente considerando uma possível conversão bidirecional entre 3-MCPD e glicidol no curso da análise conforme reportada por alguns autores. ${ }^{102} \mathrm{~A}$ segunda alternativa envolve a conversão dos ésteres de glicidol em outras espécies, como monoésteres de 3-monobromopropano-1,2-diol ou 3-metoxipropano-1,2-diol, antes da etapa de transesterificação. ${ }^{103,104}$

O desempenho dos métodos desenvolvidos para a determinação de ésteres de glicidol ainda não foi avaliado em ensaios de proficiência. Os poucos estudos que têm feito uma análise comparativa entre os procedimentos diretos e indiretos têm mostrado resultados limitados e controversos, indicando mais uma vez o impacto da técnica analítica indireta utilizada. ${ }^{70,105}$

Em relação à exposição aos ésteres de glicidol e aos riscos que estes compostos podem representar à saúde humana, poucas informações encontram-se disponíveis até o momento. Desde 2011, o CCCF também tem solicitado uma avaliação toxicológica completa destes compostos ao JECFA ${ }^{86,87}$ De maneira geral, as mesmas considerações estabelecidas para os ésteres de 3-MCPD têm sido assumidas, especialmente no que se refere à extensão da hidrólise durante o processo digestivo, à biodisponibilidade de glicidol a partir de seus ésteres, ao potencial tóxico do glicidol livre e à identificação de medidas que possam reduzir a formação destes contaminantes.

O desenvolvimento de estratégias de mitigação de ésteres de glicidol tem sido direcionado principalmente ao processo de refino do óleo de palma. Pudel e colaboradores ${ }^{52}$ estudaram as diferentes etapas de pré-tratamento do óleo antes deste seguir para o processo de desodorização. A degomagem aquosa seguida pelo branqueamento revelou um efeito positivo na redução da formação dos ésteres de glicidol, o que possivelmente está associado à remoção de precursores dos contaminantes ou de catalisadores da reação, juntamente com os fosfolipídios.

Outro fator importante na redução dos contaminantes está relacionado diretamente à qualidade do óleo. Conforme mencionado anteriormente, a maior parte dos DAGs presentes no óleo de palma bruto é proveniente da hidrólise dos TAGs pelas lipases. Sendo assim, o fator primordial seria a obtenção do óleo a partir dos frutos colhidos no menor período de tempo possível, evitando assim a atividade enzimática.

É importante também salientar que o teor de ácidos graxos livres (AGLs) é o principal indicador de qualidade do óleo utilizado pela indústria e este é geralmente separado em diferentes tanques de acordo com seu teor de AGLs quando da sua chegada à indústria. Segundo Craft e colaboradores, ${ }^{98}$ análises da composição lipídica de amostras de óleo de palma bruto confirmaram uma correlação linear entre o nível de DAGs e AGLs ( $\left.\mathrm{R}^{2}=0,8\right)$, o que possibilita estimar que 3-4\% de DAGs correspondem a aproximadamente 1,9-2,5\% de AGLs. Este cálculo simples fornece um limite máximo de AGLs que a matéria-prima deveria conter de forma a evitar uma formação excessiva de ésteres de glicidol durante o refino.

\section{CONCLUSÕES}

Recentes estudos têm demonstrado que ésteres de cloropropanóis, em especial ésteres de 3-MCPD, estão largamente distribuídos nos alimentos e ingredientes alimentícios, em quantidades muito superiores às de suas formas livres. De maneira geral, há duas categorias de produtos nas quais a ocorrência de ésteres de 3-MCPD deve ser mais significativa: uma delas se refere a alimentos processados termicamente enquanto a outra diz respeito a óleos, gorduras e alimentos fritos ou ricos em gorduras. Entretanto, a base de dados disponível ainda é limitada e a maior parte desta está direcionada à contaminação do óleo de palma.

Certamente, a falta de consenso sobre a confiabilidade dos métodos analíticos está associada a esta limitação. A possibilidade de formação de 3-MCPD durante a análise é um fator que se soma às incertezas e dificulta a interpretação dos resultados. Embora progressos significativos já tenham sido obtidos neste campo de pesquisa, há uma necessidade indiscutível de harmonizar as informações disponíveis, o que pode ser conseguido através de uma maior disponibilidade de materiais de referência e da validação dos métodos por estudos colaborativos internacionais.

Importantes avanços têm sido alcançados em relação ao verdadeiro envolvimento de acilgliceróis e fontes de cloreto no mecanismo de formação dos compostos. As recentes evidências de que os ésteres de 3-MCPD são formados principalmente a partir de TAGs e espécies de cloro orgânico e inorgânico resultantes do metabolismo endógeno da planta e da contaminação ambiental deverão contribuir para o desenvolvimento de estratégias que minimizem sua formação, o que ainda é considerado um desafio. A colaboração do setor industrial é fundamental para o sucesso destas pesquisas. Considera-se também desejável que a contaminação de alimentos processados, tais como alimentos fritos, seja mais bem compreendida.

A descoberta da presença de ésteres de glicidol em óleos refinados também tem motivado diversos estudos. Sem dúvida, a base de dados sobre estes compostos precisa ser ampliada assim como os métodos analíticos necessitam ser harmonizados. As condições de processo que favorecem a formação dos ésteres de glicidol parecem ser diferentes e mais evidentes que aquelas envolvidas na formação dos ésteres de 3-MCPD, o que sugere um grande potencial para mitigação dos compostos.

Do ponto de vista toxicológico, as preocupações inicialmente levantadas sobre o potencial de 3-MCPD e glicidol serem liberados a partir de seus ésteres durante a digestão parecem ser pertinentes. A significativa biodisponibilidade do 3-MCPD a partir de seus diésteres sugere a importância da identificação e quantificação dessas espécies nos alimentos. Informações toxicológicas mais detalhadas são fundamentais para determinar o cenário atual do risco à saúde associado à presença destes compostos em alimentos e ajudar a definir prioridades em gerenciamento do risco de forma a reduzir a exposição da população a estes contaminantes.

\section{AGRADECIMENTOS}

À Fundação de Amparo à Pesquisa do Estado de São Paulo (FAPESP) pelo apoio concedido (Processo 2011/08936-0). 


\section{REFERENCIAS}

1. Lineback, D. R.; Stadler, R. H. Em Process-induced food toxicants: occurrence, formation, mitigation, and health risks; Stadler, R. H.; Lineback, D. R., eds.; John Wiley \& Sons Inc.: New York, 2009, cap. 1.

2. Ender, F.; Havre, G.; Helgebostad, A.; Koppamg, N.; Madsen, R.; Ceh, L.; Naturwissenschaften 1964, 51, 637.

3. Sugimura, T.; Nagao, N.; Kawachi, T.; Honda, M.; Yahagi, T.; Seino, Y.; Stao, S.; Matsukura, N.; Matsushima, T.; Shirai, A.; Sawamura, M.; Matsumoto, H. Em Origins of human cancer, Book C; Hiatt, H. H.; Watson, J. D.; Winstein, J. A., eds.; Cold Spring Harbor Laboratory Press: New York, 1977.

4. Davídek, J.; Velísek, J.; Kubelka, V.; Janícek, G.; Simicová, Z.; Proceedings of Euro Food Chem I, Áustria, Viena, 1982.

5. Tareke, E.; Rydberg, P.; Karlsson, P.; Eriksson, S.; Törnqvist, M.; J. Agric. Food Chem. 2002, 50, 4998.

6. http://www.fda.gov/Food/FoodborneIllnessContaminants/ ChemicalContaminants/ucm078439.htm, acessada em Agosto 2013.

7. Svejkovská, B.; Novotny, O.; Divinová, V.; Réblová, Z.; Dolezal, M.; Velísek, J.; Czech J. Food Sci. 2004, 22, 190.

8. http://www.bfr.bund.de/cm/349/infant_formula_and_follow_up_ formula_may_contain_harmful_3_mcpd_fatty_acid_esters.pdf, acessada em Agosto 2013.

9. http://www.efsa.europa.eu/en/efsajournal/doc/1048.pdf, acessada em Agosto 2013.

10. http://www.aocs.org/Resources/content.cfm?ItemNumber=1011\&navIt emNumber=702, acessada em Agosto 2013.

11. http://www.ilsi.org/Europe/Publications/Final\%20version $\% 203 \% 20$ MCPD\%20esters.pdf, acessada em Agosto 2013.

12. http://monographs.iarc.fr/ENG/Monographs/vol101/mono101-010.pdf, acessada em Agosto 2013.

13. Velísek, J. Em Process-induced food toxicants: occurrence, formation, mitigation, and health risks; Stadler, R. H.; Lineback, D. R., eds.; John Wiley \& Sons Inc.: New York, 2009, cap. 6.3.

14. Velísek, J.; Davídek, J.; Hajslová, J.; Kubelka, V.; Janícek, G.; Mánková, B.; Z. Lebensm. Unters. Forsch. 1978, 167, 241.

15. Velísek, J.; Davídek, J.; Kubelka, V.; Janícek, G.; Svobodová, Z.; Simicová, Z.; J. Agric. Food Chem. 1980, 28, 1142.

16. Velísek, J.; Dolezal, M.; Crews, C.; Dvorák, T.; Czech J. Food Sci. 2002, $20,161$.

17. Seefelder, W.; Scholz, G.; Schilter, B.; Eur. J. Lipid Sci. Technol. 2011, 113,319 .

18. Hamlet, C. G.; Sadd, P. A.; Czech J. Food Sci. 2004, 22, 259.

19. Zelinková, Z.; Dolezal, M.; Velísek, J.; Eur. Food Res. Technol. 2009, 228, 571.

20. Kuhlmann, J.; Eur. J. Lipid Sci. Technol. 2011, 113, 335.

21. Seefelder, W.; Varga, N.; Studer, A.; Williamson, G.; Scanlan, F. P.; Stadler, R. H.; Food Addit. Contam. 2007, 25, 391.

22. Buhrke, T.; Weißhaar, R.; Lampen, A.; Arch. Toxicol. 2011, 85, 1201.

23. Desnuelle, P.; Savary, P.; J. Lipid Res. 1963, 4, 369.

24. Dupont, J. L. Em Lipid metabolism and health; Moffatt, R. J.; Stamford, B., eds.; CRC Press, Taylor \& Francis Group: Boca Raton, 2006, cap. 3.

25. http://www.efsa.europa.eu/de/supporting/doc/187e.pdf, acessada em Agosto 2013.

26. Abraham, K.; Appel, K. E.; Berger-Preiss, E.; Apel, E.; Gerling, S.; Mielke, H.; Creutzenberg, O.; Lampen, A.; Arch. Toxicol. 2013, 87, 649.

27. Tee, V. P.; Shahrim, Z.; Nesaretnam, K.; Abstracts of 9th Euro Fed lipid Congress, Rotterdam, Holanda, 2011.

28. Liu, M.; Gao, B.-Y.; Qin, F.; Wub, P.-P.; Shi, H.-M.; Luo, W.; Mad, A.N.; Jiang, Y.-R.; Xu, X.-B.; Yu, L.-L.; Food Chem. Toxicol. 2012, 50, 3785 .

29. Bakhiya, N.; Abraham, K.; Gurtler, R.; Appel, K. E.; Lampen, A.; Mol. Nutr. Food Res. 2011, 55, 509.
30. Cho, W.-S.; Han, B. S.; Nam, K. T.; Park, K.; Choi, M.; Kim, S. H.; Jeong, J.; Jang, D. D.; Food Chem. Toxicol. 2008, 46, 3172.

31. http://ec.europa.eu/food/fs/sc/scf/out91_en.pdf, acessada em Agosto 2013.

32. http://www.inchem.org/documents/jecfa/jecmono/v48je18.htm, acessada em Agosto 2013.

33. Hwang, M.; Yoon, E.; Kim, J.; Jang, D. D.; Yoo, T. M.; Regul. Toxicol. Pharmacol. 2009, 53, 102.

34. Velísek, J.; Davídek, J.; Kubelka, V.; Bartosová, J.; Tuèková, A.; Hajslová, J.; Janícek, G.; Z. Lebensm. Unters. Forsch. 1979, 12, 234.

35. Davídek, J.; Velísek, J.; Kubelka, V.; Janícek, G.; Simicová, Z.; Z. Lebensm. Unters. Forsch. 1980, 171, 14.

36. Gardner, A.; Yurawecz, M.; Cunningham, W.; Diachenko, G.; Mazzola, E.; Brumley, W.; Bull. Environ. Contam. Toxicol. 1983, 31, 625.

37. Cerbulis, J.; Parks, O. W.; Liu, R. H.; Piotrowski, E. G.; Farrell, H. M.; J. Agric. Food Chem. 1984, 32, 474.

38. Zelinková, Z.; Svejkovská, B.; Velísek, J.; Dolezal, M.; Food Addit. Contam. 2006, 23, 1290.

39. Dolezal, M.; Chaloupská, M.; Divinová, V.; Svejkovská, B.; Velísek, J.; Eur. Food Res. Technol. 2005, 221, 221.

40. Divinová, V.; Dolezal, M.; Velísek, J.; Czech J. Food Sci. 2007, 25, 39.

41. Zelinková, Z.; Novotný, O.; Schrek, J.; Velísek, J.; Hajslová, J.; Dolezal, M.; Food Addit. Contam. 2008, 25, 669.

42. Karsulínová, L.; Folprechtová, B.; Dolezal, M.; Dostálová, J.; Velísek, J.; Czech J. Food Sci. 2007, 25, 257.

43. Weißhaar, R.; Eur. J. Lipid Sci. Technol. 2011, 113, 304.

44. Zelinková, Z.; Dolezal, M.; Velísek, J.; Czech J. Food Sci. 2009, 27, S421.

45. Ilko, V.; Zelinková, Z.; Dolezal, M.; Velísek, J.; Czech J. Food Sci. 2011, $29,411$.

46. Habermeyer, M.; Guth, S.; Eisenbrand, G.; Eur. J. Lipid Sci. Technol. 2011, 113, 314.

47. Dubois, M.; Tarres, A.; Goldmann, T.; Empl, A. M.; Donaubauer, A.; Seefelder, W.; J. Chromatogr. A 2012, 1236, 189.

48. Yamazaki, K.; Ogiso, M.; Isagawa, S.; Urushiyama, T.; Ukena, T.; Kibune, N.; Food Addit. Contam. 2013, 30, 52.

49. Velísek, J.; Calta, P.; Crews, C.; Hasnip, S.; Dolezal, M.; Czech J. Food Sci. 2003, 21, 153

50. Calta, P.; Velísek, J.; Dolezal, M.; Hasnip, S.; Crews, C.; Réblová, Z.; Eur. Food Res. Technol. 2004, 218, 501.

51. Svejkovská, B.; Dolezal, M.; Velísek, J.; Czech J. Food Sci. 2006, 24, 172.

52. Pudel, F.; Benecke, P.; Fehling, P.; Freudenstein, A.; Mattaus, B.; Schwaf, A.; Eur. J. Lipid Sci. Technol. 2011, 113, 368.

53. Sampaio, K. A.; Ceriani, R.; Silva, S. M.; Taham, T.; Meirelles, A. J. A.; Food Bioprod. Process. 2011, 89, 383.

54. Basiron, Y. Em Bailey's Industrial oil \& fat products; Shahidi, F., ed.; John Wiley \& Sons Inc.: New York, 2005, cap. 2.8.

55. Sampaio, K. A.; Ayala, J. V.; Silva, S. M.; Ceriani, R.; Verhé, R.; Meirelles, A. J. A.; J. Am. Oil Chem. Soc. 2013, 90, 191.

56. Franke, K.; Strijowski, U.; Fleck, G.; Pudel, F.; LWT Food Sci. Technol. 2009, 42,1751 .

57. Hrncirik, K.; Van Duijn, G.; Eur. J. Lipid Sci. Technol. 2011, 113, 374.

58. Weißhaar, R.; Eur. J. Lipid Sci. Technol. 2008, 110, 671.

59. Hamlet, C. G.; Asuncion, L.; Velísek, J.; Dolezal, M.; Zelinková, Z.; Crews, C.; Eur. J. Lipid Sci. Technol. 2011, 113, 279.

60. Collier, P. D.; Cromie, D. D. O.; Davies, A. P.; J. Am. Oil Chem. Soc. 1991, 68, 785.

61. Rahn, A. K. K.; Yaylayan, V. A.; Eur. J. Lipid Sci. Technol. 2011, 113, 323.

62. Craft, B. D.; Chiodini, A.; Garst, J.; Granvogl, M.; Food Addit. Contam. 2013, 30, 46.

63. Rahn, A. K. K.; Yaylayan, V. A.; Eur. J. Lipid Sci. Technol. 2011, 113, 330. 
64. Weißhaar, R.; Perz, R.; Eur. J. Lipid Sci. Technol. 2010, 112, 158.

65. Long, K.; Jamari, M. A.; Ishak, A.; Yeok, L. J.; Latif, R. A.; Ahmadilfitri, Lai, O. M.; Eur. J. Lipid Sci. Technol. 2005, 107, 754.

66. Matthäus, B.; Pudel, F.; Fehling, P.; Vosmann, K.; Freudenstein, A.; Eur. J. Lipid Sci. Technol. 2011, 113, 380.

67. Zulkurnain, M.; Lai, O. M.; Latip, R. A.; Nehdi, I. A.; Ling, T. C.; Tan, C. P.; Food Chem. 2012, 135, 799.

68. Destaillats, F.; Craft, B. D.; Sandoz, L.; Nagy, K.; Food Addit. Contam. 2012, 29, 29.

69. Nagy, K.; Sandoz, L.; Craft, B. D.; Destaillats, F.; Food Addit. Contam. 2011, 28, 1492.

70. Crews, C.; Chiodini, A.; Granvogl, M.; Hamlet, C.; Hrncirik, K.; Kuhlmann, J.; Lampen, A.; Scholz, G.; Weißhaar, R.; Wenzl, T.; Jasti P. R.; Seefelder, W.; Food Addit. Contam. 2013, 30, 11.

71. Divinová, V.; Svejkovská, B.; Dolezal, M.; Velísek, J.; Czech J. Food Sci. 2004, 22, 182.

72. Weißhaar, R.; Eur. J. Lipid Sci. Technol. 2008, 110, 183.

73. Küsters, K.; Bimber, U.; Ossenbrüggen, A.; Reeser, S.; Gallitzendorfer, R.; Gerhartz, M.; J. Agric. Food Chem. 2010, 58, 6570.

74. Miyazaki, K.; Koyama, K.; Sasako, H.; Hirao, T.; J. Am. Oil Chem. Soc. 2012, 89, 1403.

75. Chung, S. W. C.; Chan, B. T. P.; Chromatographia. 2012, 75, 1049.

76. Haines, T. D.; Adlaf, K. J.; Pierceall, R. M.; Lee, I.; Venkitasubramanian, P.; Collison, M. W.; J. Am. Oil Chem. Soc. 2011, 88, 1.

77. Hori, K.; Koriyama, N.; Omori, H.; Kuriyama, M.; Arishima, T.; Tsumura, K.; LWT Food Sci. Technol. 2012, 48, 204.

78. Moravcova, E.; Vaclavik, L.; Lacina, O.; Hrbek, V.; Riddellova, K.; Hajslova, J.; Anal. Bioanal. Chem. 2012, 402, 2871.

79. Hrncirik, K.; Zelinková, Z.; Ermacora, A.; Eur. J. Lipid Sci. Technol. 2011, 113, 361.

80. Fiebig, H. J.; Eur. J. Lipid Sci. Technol. 2011, 113, 393.

81. http://www.dgfett.de/methods/, acessada em Agosto 2013.

82. Karasek, L.; Wenzl, T.; Ulberth, F.; Eur. J. Lipid Sci. Technol. 2011, 113, 1433.

83. http://www.cfs.gov.hk/english/programme/programme_rafs/files/ programme_rafs_fc_01_33_3MCPD_Report.pdf, acessada em Agosto 2013.

84. http://www.cclac.org/documentos/CCCF/2009/1\%20Alinorm/al32_41. pdf, acessada em Agosto 2013.

85. http://www.cclac.org/documentos/CCCF/2010/1\%20Alinorm/al33_41e. pdf, acessada em Agosto 2013.
86. http://www.cclac.org/documentos/CCCF/2011/1\%20Alinorm/REP11 CFe.pdf, acessada em Agosto 2013.

87. http://www.codexalimentarius.nl/sites/default/files/page_attachtment/ REP12_CFe.pdf, acessada em Agosto 2013.

88. Craft, B. D.; Nagy, K.; Sandoz, L.; Destaillats, F.; Food Addit. Contam. 2012, 29, 354

89. Ramli, M. R.; Siew, W. L.; Ibrahim, N. A.; Hussein, R.; Kuntom, A.; Razak, R. A. A.; Nesaretnam, K.; J. Am. Oil Chem. Soc. 2011, 88, 1839.

90. Zulkurnain, M.; Lai, O. M.; Tan, S. C.; Abdul Latip, R.; Tan, C. P.; J. Agric. Food Chem. 2013, 61, 3341.

91. Bornscheuer, U. T.; Hesseler, M.; Eur. J. Lipid Sci. Technol. 2010, 112, 552 .

92. Strijowski, U.; Heinz, V.; Franke, K.; Eur. J. Lipid Sci. Technol. 2011, $113,387$.

93. http://ntp.niehs.nih.gov/ntp/htdocs/LT_rpts/tr374.pdf, acessada em Agosto 2013.

94. http://ntp.niehs.nih.gov/ntp/htdocs/GMM_rpts/gmm13.pdf, acessada em Agosto 2013.

95. http://monographs.iarc.fr/ENG/Monographs/vol77/volume77.pdf, acessada em Agosto 2013.

96. Frank, N.; Dubois, M.; Scholz, G.; Seefelder, W.; Chuat, J. -Y.; Schilter, B.; Food Addit. Contam. 2013, 30, 69.

97. Schilter, B.; Scholz, G.; Seefelder, W.; Eur. J. Lipid Sci. Technol. 2011, $113,309$.

98. Craft, B. D.; Nagy, K.; Seefelder, W.; Dubois, M.; Destaillats, F.; Food Chem. 2012, 132, 73.

99. Destaillats, F.; Craft, B. D.; Dubois, M.; Nagy, K.; Food Chem. 2012, 131,1391

100. Maswkawa, Y.; Shiro, H.; Nakamura, S.; Kondo, N.; Norikazu, J.; Suzuki, N.; Ooi, N.; Kudo, N.; J. Oleo Sci. 2010, 59, 81.

101. Blumhorst, M. R.; Venkitasubramanian, P.; Collison, M. W.; J. Am. Oil Chem. Soc. 2011, 88, 1275.

102. Kaze, N.; Sato, H.; Yamamoto, H.; Watanabe, Y.; J. Am. Oil Chem. Soc. 2011, 88, 1143.

103. Ermacora, A.; Hrncirik, K.; J. Am. Oil Chem. Soc. 2013, 90, 1.

104. Küsters, M.; Bimber, U.; Reeser, S.; Gallitzendörfer, R.; Gerhartz, M.; J. Agric. Food Chem. 2011, 59, 6263.

105. Shimizu, M.; Kudo, N.; Shiro, H.; Yasunaga, K.; Masukawa, Y.; Katsuragi, Y.; Yasumasu, T.; J. Oleo Sci. 2010, 59, 535. 